\title{
Primary De novo intra-osseous carcinoma of mandible: a rare case report
}

\begin{abstract}
Primary intraosseous carcinoma is a rare neoplastic lesion, which occurs in the jaws. We report a new case of unusual tumor, which is discussed with its clinical, histopathological aspects. A 63yr old male patient presented with pain in the lower right back tooth region and swelling, since 3 months. In the present case the clinical, histological and radiological features of intraosseous carcinoma are discussed. Hence the aggressiveness of tumor highlights the present case.
\end{abstract}

Keywords: primary intraosseous carcinoma, odontogenic tumor, squamous cell carcinoma

\author{
Volume 2 Issue 5 - 2017
Mithare Sangmesh,' Veerbhadra Kalyani,' Kotya Naik Maloth,' Swathi V Reddy'
'Department of Oral Medicine and Radiology, India
${ }^{2}$ Department of Oral \& Maxillofacial Surgery, India

Correspondence: Kotya Naik Maloth, Department of Oral Medicine and Radiology, Mamata Dental College and Hospital, Khammam, Telangana, India, Tel 919885617131,

Email dr.kotyanaik.maloth@gmail.com

Received: February 28, 2017| Published: March 21, 2017

\section{Introduction}

Carcinoma in the mouth and the jaws usually arises from the epithelial lining of the oral cavity or rarely from the salivary glands. But carcinoma within the mandible as primary tumor is very rare. Generally the primary tumor may arise from the breast, thyroid, kidney or lungs and secondaries are seeded in the mandible. Pindborg et al. ${ }^{1}$ used the term primary intraosseous carcinoma. ${ }^{2,3}$ Usually this type of carcinoma may arise from the jaw bone and with no initial connection with oral mucosa. ${ }^{4}$ The definite diagnosis of primary intraosseous carcinoma is often difficult as the lesion must be distinguished from the alveolar carcinoma that may invade the bone from the overlying soft tissues; from the tumor that have metastasized to the jaws from a distant site; from the primary tumor of maxillary sinus origin. ${ }^{2}$ Since the most common symptoms of primary intraosseous carcinoma are swelling and persistent pain, the diagnosis is often difficult. ${ }^{1,2}$ Hence a clinical case presenting with similar findings is presented.

\section{Case report}

A 63year old male patient reported to our department with a chief complaint of pain and swelling in the right lower back teeth region since 3months; pain was intermittent, shooting type, which aggravates on mastication and was relieved on taking medication. Patient had undergone multiple extractions in previous dental visits. Patient used to smoke 2 packets of cigarettes/day since $45 \mathrm{yrs}$. On extra oral examination (Figure 1) a diffuse swelling on the right side of the face, measuring approx. $4 \times 5 \mathrm{~cm}$ extending superior-inferiorly from the ear's tragus to the mandible's angle and anterior-posteriorly from the the ear's lobe to the mouth's corner, was detectable. Overlying skin was normal, no visible pulsations were seen. On palpation the swelling was tender; no local rise of temperature was felt. It was non-compressible, non-reducible, non-pulsatile. A single right submandibular lymph node which was firm, non-tender, measuring about $1 \times 1 \mathrm{~cm}$ in size, was palpable. It was hard in consistency and fixed to underlying structures. Mouth opening was reduced, it was about $3 \mathrm{cms}$. On Intra oral examination (Figure 2) an oval solitary diffuse swelling measuring approx $3 \times 3 \mathrm{cms}$ was seen in the right molar region. It extended anterior-posteriorly from $2^{\text {nd }}$ premolar region to the pterygomandibular raphe, and superior-inferiorly from the level of occlusion of upper $3^{\text {rd }}$ molar region to the lower buccal vestibule: buccal vestibule was obliterated. Expansion of buccal and lingual cortical plates could be seen in that region; ulceration was not seen. On palpation, the swelling was tender, firm in consistency. It was non-fluctuant and non-reducible and no palpable pulsations were felt. On FNAC no aspirate was found. Based on the clinical findings a provisional diagnosis of benign odontogenic tumor was made with a differential diagnosis of pericoronal abscess, infected dentigerous cyst, ameloblastoma, odontogenic keratocyst, pterygomandibular space infection, carcinoma of mandible.

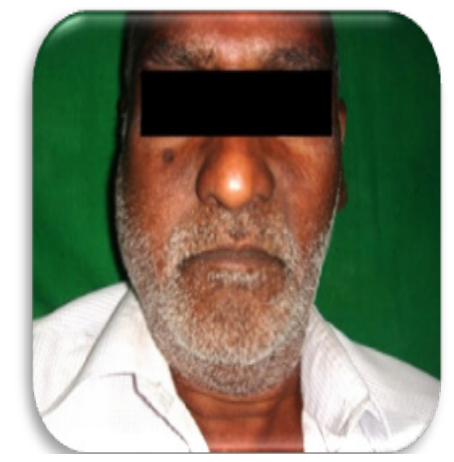

Figure I Profile View.

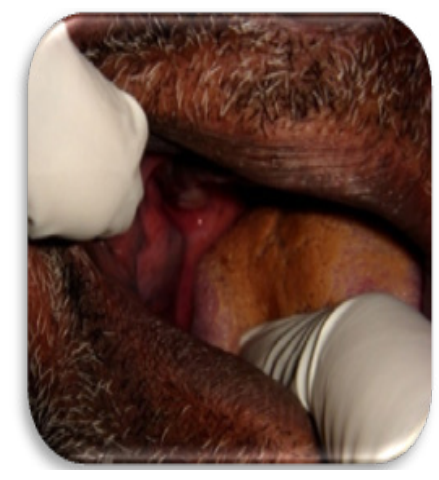

Figure 2 Intra-Oral View. 


\section{Investigations}

Routine investigations like complete blood picture, blood sugar level VDRL, HIV and hepatitis B screening were performed and showed no abnormality. Radiographs were taken: Right Lateral Oblique view (Figure 3) and Orthopantomograph (Figure 4) reveled edentulous maxilla and partially edentulous mandible (only one tooth in mandible) with an irregular radiolucency in the posterior part of the mandible on right side, involving the angle area and extending into the ramus. One tooth appeared to be floating inside the radiolucency. Periphery of the lesion showed ragged borders, features suggestive of squamous cell carcinoma. Chest radiograph showed no abnormality Figure 5. CT of the neck Figure 6 showed irregular soft tissue density involving the alveolar margin and degenerative changes of the cervical spine. Incisional biopsy was done and two biopsy specimens were taken from the right retromolar region measuring about $1.5 \mathrm{~cm} \times 0.5 \mathrm{~cm} \times 0.3 \mathrm{cms}$ and $0.5 \mathrm{~cm} \times 0.3 \mathrm{~cm} \times 0.2 \mathrm{~cm}$, respectively. Histopathological features Figure 7 showed dysplastic epithelial cells invading the connective tissue stroma suggesting a diagnosis of a moderately differentiated squamous cell carcinoma.

After thorough clinical, radiological and histopathological evaluation, the patient was referred to higher oncology institute for further treatment; Commando surgery was planned along with right side functional neck dissection and hemimandibulectomy followed by reconstruction. Few radiotherapy sessions were also planned as a palliative management. Unfortunately, the patient was not willing for further treatment as he couldn't afford for the treatment costs. We followed him up for 1year (Figure $8 \&$ 9) where after he ensued death secondary to generalized debilitation, secondary infection and sepsis.

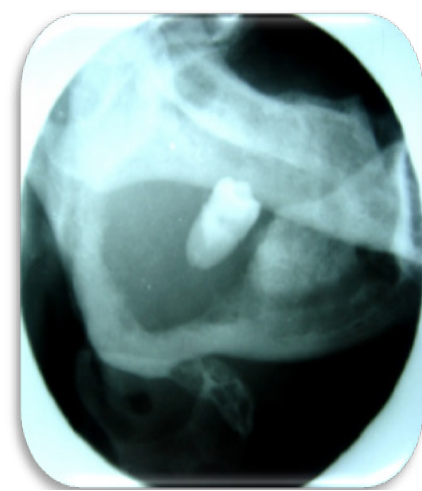

Figure 3 Lateral oblique view reveals ill-defined radiolucency and tooth appears to be floating in the radiolucency.

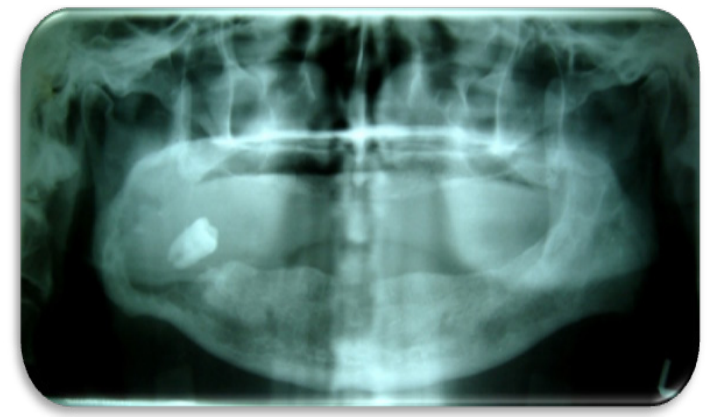

Figure 4 Orthopantomograph shows edentulous maxilla and partially edentulous mandible (only one tooth in mandible irt 48). III defined radiolucency seen in the right posterior part of the mandible involving angle area and extending into ramus.
Figure 5 Chest X-ray.
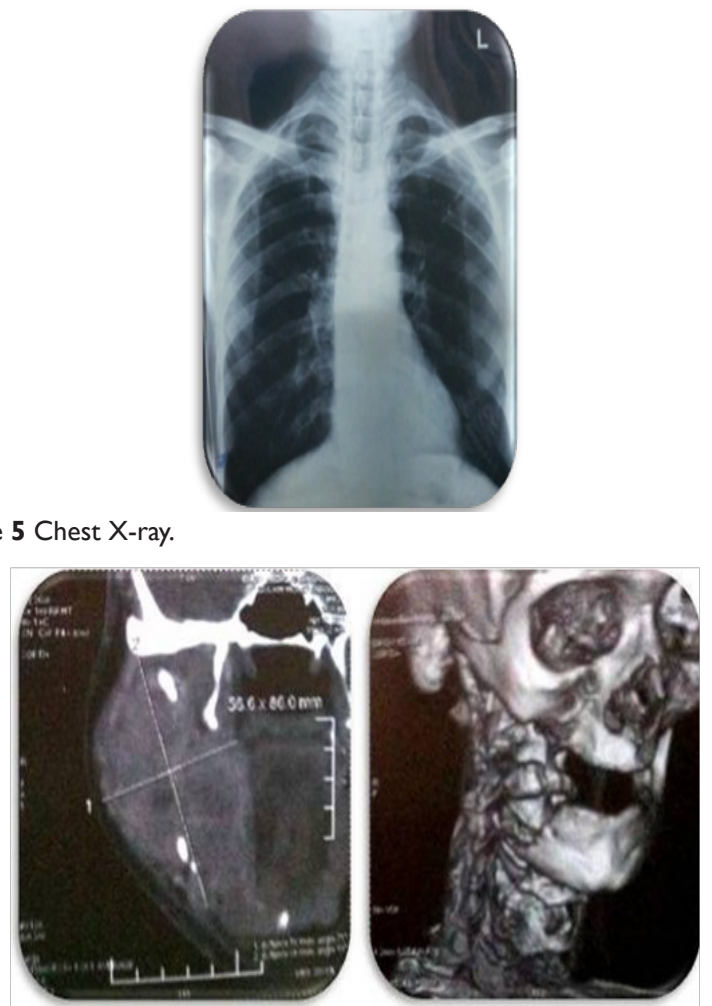

Figure 6 Coronal \& 3D view of computed tomography showing irregular soft tissue density involving the alveolar margin and degenerative changes of cervical spine.

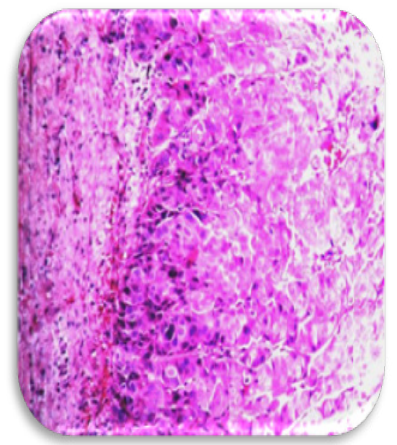

Figure 7 Histopathology Picture reveals dysplastic epithelial cells invading the connective tissue stroma.

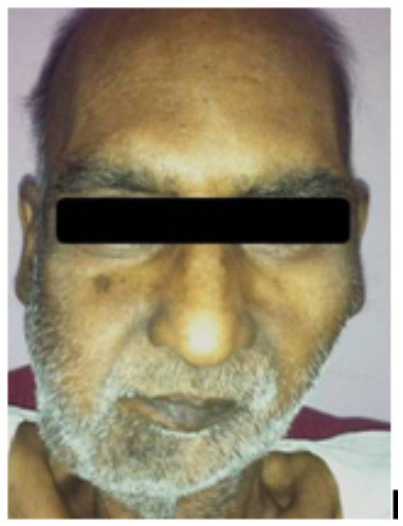

Figure 8 After lyear follow up extra oral photograph. 


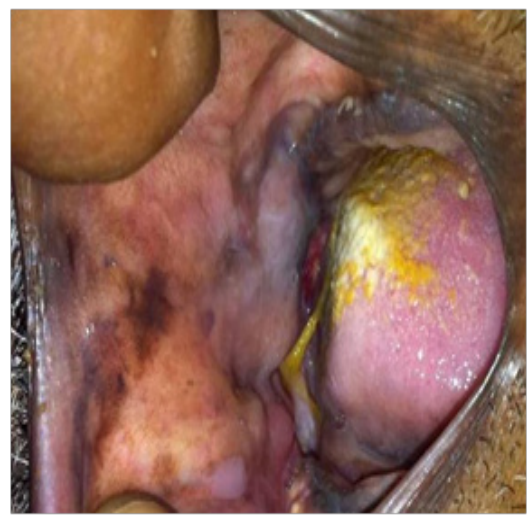

Figure 9 After lyear follow up intraoral photograph.

\section{Discussion}

Primary intraosseous carcinoma (PIOC) was first described by Loos in 1913 as a central epidermoid carcinoma of the jaw. ${ }^{5,6}$ Willis in 1948 renamed it as an intra-alveolar epidermoid carcinoma. ${ }^{7}$ In 1971 Pindborg coined the term Primary intraosseous carcinoma (PIOC) ${ }^{8}$ According to World Health Organisation (WHO) primary intraosseous carcinoma is defined as "A Squamous cell carcinoma arising with in the jaw, having no initial connection with the oral mucosa and presumably developing from residues of the odontogenic epithelium". ${ }^{7}$ There are several classifications present, but the widely accepted is Waldron and Mustoe's classification according to the PIOC origins. ${ }^{3-6,8}$

a. Type 1: PIOC ex Odontogenic cyst.

b. Type 2a: Malignant Ameloblastoma.

c. Type 2b: Ameloblastic carcinoma arising de novo, ex-Ameloblastoma or ex-odontogenic cyst.

d. Type 3: PIOC arising de novo.

i. Keratinizing type

ii. Non-keratinizing type

e. Type 4: Intraosseous mucoepidermoid carcinoma.

PIOC affects patients ranging from 4-90yrs of age with mean age of 52 years. ${ }^{9,10}$ It is more frequently located in the mandible than maxilla, ${ }^{3-6,9,10}$ mostly involving the posterior region of the jaw. ${ }^{10}$ It affects men more than women with the ratio about 2.2:1. Suei et al., ${ }^{10}$ proposed a few diagnostic criteria for PIOC:

A. No ulcer formation must be present on the overlying oral mucosa except when due to such cases as trauma or tooth extractions, to differentiate PIOCs from squamous cell carcinomas of surface mucosal origin,

B. There must be histological evidence of squamous cell carcinoma and

C. Chest radiographs must be clear at the time of diagnosis and throughout a follow-up period of at least 6 months to rule out a distant primary tumor. ${ }^{11}$ Lucas presumed that carcinoma may arise from the odontogenic rests or from the epithelium entrapped in the deeper structures during fusion of facial process. ${ }^{5,12}$ For a carcinoma to develop the presence of epithelium is mandatory and it can include remnants of dental lamina, remnants of Hertwig's epithe- lial root sheath, remnants of enamel organ, odontogenic tumors or odontogenic cyst lining, entrapped epithelium during fusion of facial process and salivary gland inclusions. ${ }^{5}$ The most common complaint of the patient is pain, caused by mandibular nerve infiltration; paresthesia, accelerated growth with swelling and trismus are the most common symptoms. ${ }^{8,10}$ According to Thomas et al the clinical feature manifested in the PIOC are pain $54.8 \%$, swelling of the jaw $51.6 \%$ and sensory disturbances $16.1 \% .{ }^{13}$ In our case, pain, swelling and trismus were seen.

The radiographic examination is one of the most effective means of detecting PIOCs. ${ }^{14}$ Nolan reported that PIOCs that grow slowly usually has well-defined, smoothly contoured border. ${ }^{2}$ Whereas in our case lateral oblique view showed completely radiolucent lesion with well-defined borders. Kaffe et al., ${ }^{14}$ have proposed that an important feature of PIOC is the presence of indistinct margins without sclerotic outline..$^{10,14}$

The histological features of PIOC usually indicate absence of keratinisation as described by Shear. ${ }^{15}$ However dysplastic epithelial cells invading the connective tissue were seen in our case. Usually histological features of PIOC are not pathognomonic and often difficult, because of the histological variations of odontogenic epithelial components in odontogenic cysts and tumors. ${ }^{16}$

The prognosis of PIOC is quite poor and importance should be given to early diagnosis, so that suitable treatment can be given at the earliest. ${ }^{17}$ Thomas et al. ${ }^{13}$ reported that overall survival rates of 1,2 and 3years were $75.7 \%, 62.1 \%$, and $37.8 \%$ respectively. ${ }^{6}$

The primary intraosseous squamous cell carcinoma is considered a highly malignant tumor that should be treated aggressively. In one study out of 37 patients, the treated modalities were surgery alone in 14 patients (37.8\%), adjuvant radiotherapy in 18 patients $(48.7 \%)$ and both chemotherapy and radiotherapy in 5 patients $(13.5 \%) .{ }^{10}$

\section{Conclusion}

The importance of this case is that it illustrates the central origin of the tumor, presenting as a dental problem and being relatively rapidly growing. The diagnosis of a PIOC is rare, but it is often worth considering it in any differential diagnosis of jaw radiolucency. We would advocate that any radiolucency should either be biopsied at an early stage or followed-up closely with regular radiographs. The prognosis of PIOC is quite poor and importance should be given to early diagnosis so that suitable treatment can be given at the earliest.

\section{Acknowledgements}

None.

\section{Conflict of interest}

Author declares that there is no conflict of interest.

\section{References}

1. McGowan RH. Primary intra-alveolar carcinoma. A difficult diagnosis. Br J Oral Surg. 1980;18(3):259-265.

2. Hwang EH, Choi YS, Lee SR. Primary intraosseous carcinoma of the mandible. Korean J Oral and Maxillofacial Radiol. 2005;35(4):235-239.

3. Shambhulingappa P, Sheikh S, Puri N, et al. Primary intraosseous carcinoma of mandible: An update on review of literature with a case report. J Clin Exp Dent. 2010;2(2):e91-e95. 
4. Nandimath K, Naikmasur VG, Babshet M. Primary intraosseous carcinoma of mandible: A case report. Dent Res J. 2011;8(2):102-107.

5. Sengupta S, Vij H, Vij R. Primary intraosseous carcinoma of the mandible: A report of two cases. J Oral Maxillofac Pathol. 2010;14(2):69-72.

6. Gallego L, Junquera L, Villarreal P, et al. Primary de novo intraosseous carcinoma: Report of a new case. Med Oral Pathol Oral Cir Buccal. 2010;15(1):e48-e51

7. Lu CC, Chang KM, Liu CJ. Primary intraosseous carcinoma of mandible: A case report. Chin J Oral Maxillofac Surg. 2004;15:38-47.

8. Lin $\mathrm{YJ}$, Chen $\mathrm{CH}$, Wang $\mathrm{WC}$, et al. Case report Primary intraosseous carcinoma of the mandible. Dentomaxillofacial Radiology. $2005 ; 34: 112-116$

9. Narcisse Z, Jacques P, Janine R, et al. Primary intraosseous carcinoma of the jaws. Arch Otolaryngeal Head Neck Surg. 2001;127(7):794-797.

10. Huang JW, Luo HY, Li Q, et al. Primary intraosseous squamous cell carcinoma of the jaws. Clinicopathologic presentation and prognostic factors. Arch Pathol Lab Med. 2009;133(11):1834-1840.
11. Suei Y, Tanimoto K, Taguchi A, et al. Primary intraosseous carcinoma: Review of the literature and diagnostic criteria. J Oral Maxillofac Surg. 1994;52(6):580-583

12. Lucas RB. Pathology of tumors of the oral tissues. 4th ed. London: Churchill Livingstone; 1984. p. 140-141.

13. Thomas G, Pandey M, Mathew A, et al. Primary intraosseous carcinoma of the jaw: Pooled analysis of world literature and report of two new cases. Int J Oral Maxillofac Surg. 2001;30(4):349-355.

14. Kaffe I, Ardekian L, Peled M, et al. Radiological features of primary intraosseous carcinoma of the jaws: Analysis of the literature and report of a new case. Dentomaxillofacial radio. 1998;27(4):209-214.

15. Shear M. Primary intra-alveolar epidermoid carcinoma of the jaw. $J P a$ thol. 1969;97(4):645-651.

16. Anneroth G, Hansen LS. Variations in keratinizing odontogenic cysts and tumors. Oral Surg Oral Med Oral Pathol. 1982;54(5):530-545.

17. Dimitrakopoulos I, Psomaderis K, Asimaki A, et al. Primary de novo intraosseous carcinoma: report of two cases. J Oral Maxillofac Surg. 2005;63(8):1227-1230. 